\title{
Changes in water quality and the phytoplankton community associated with tilapia cage farming in tropical lakes
}

\author{
Taciana O. Miranda, Hevelim S. Lima, Bianca Galon, Alexandra C. Veronez, Marcelo S. Moretti, \\ James J. Roper and Levy C. Gomes ${ }^{\mathrm{a}}$
}

Universidade Vila Velha, Rua Comissário José Dantas de Melo, 21 Boa Vista, Vila Velha, ES 29.102-770, Brazil

Received 25 February 2016; Accepted 30 September 2016

\begin{abstract}
We examine phytoplankton community structure and how it is influenced by commercial tilapia (Oreochromis niloticus L.) cage farming in three tropical lakes in eastern Brazil. Sampling occurred during both the wet and dry seasons for two treatments - within tilapia cages and outside the cages in the lake. Total ammonia, total phosphorus, chlorophyll $a$, phycocyanin and phytoplankton were measured in all water samples. In the phytoplankton community, we estimated species richness and total abundance. Thirty-three genera of algae distributed in 8 classes were identified. The most abundant classes were Chlorophyceae and Cyanophyceae (the latter of which was the most species-rich class). In Palmas Lake, chlorophyll $a$ was constant over time (summer and winter) and location (within and outside cage farms), which may reflect the fact that fish farming is more recent in this lake. The richness and abundance of species were similar among the lakes, but Palminhas Lake tended to have more extreme values, apparently associated with the longer time fish have been farmed there. Fish farming clearly influences water quality as measured by algae species richness and abundance but is also moderated by the unique conditions in each lake and the amount of time over which the fish have been farmed. Understanding and preventing the impacts and detrimental consequences of tilapia cage farming on both the farming yield and the water quality in tropical lakes require continual monitoring.
\end{abstract}

Keywords: Phytoplankton / eutrophication / phosphorus / Cyanophyceae / Chlorophyceae

\section{Introduction}

Commercial fish farming in cages is a rapidly expanding industry in Brazil and other tropical countries (Bueno et al. 2013). Consequently, the use of natural bodies of water (lakes and lagoons) for fish farming, especially tilapia (Oreochromis niloticus L.) is increasing, along with the impact of this practice on the environment (Bueno et al. 2013). Growth in tilapia farming is due to a variety of reasons, including the rising market value and demand for fish, food security in developing countries, improved technology and the availability of technical support and high quality food for the fish (Defegu et al. 2011). At the same time, accelerated growth of the commercial fishing industry does not come without costs, including environmental impacts, especially for aquatic communities.

Commercially rearing tilapia requires a large quantity of fish food that ends up in the water, causing a dramatic increase in the nutrients in the water column, especially nitrogen and phosphorus (Jieng et al. 2013). Excessive concentrations of $\mathrm{N}$ and $\mathrm{P}$ cause eutrophication which has its own detrimental consequences for the ecological services of aquatic systems, generating ecological, economic and social costs (Bricker et al.

a Corresponding author: levy.gomes@uvv.br
2008; Sidik et al. 2008). Changes in the phytoplankton community structure and composition as a consequence of fish farming can cause the proliferation of some species of algae that then disrupt aquatic ecosystems, including fish farming itself (Sant'anna and Azevedo 2000). Algae proliferation, a reduction in dissolved oxygen, reduced water transparency and their consequences for the phytoplankton and zooplankton communities are well-known consequences of aquaculture. Commonly, proliferation of undesirable algae (including Chlorophyceae) is caused by the amplification of nutrients associated with fish farming (Wu et al. 2012). Here, we explore how tilapia cage farming influences phytoplankton community structure in eastern Brazil in the state of Espírito Santo.

\section{Materials and methods}

\subsection{Study area}

We examined the phytoplankton community in three lakes where tilapia are being farmed in a region with a complex of 69 small lakes in the Doce River watershed near the city of Linhares. The three lakes are Aguiar $\left(19^{\circ} 35^{\prime} 10^{\prime \prime} \mathrm{S}\right.$,

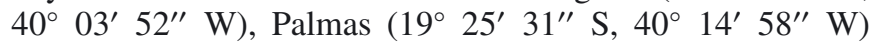


Table 1. Comparison among lakes of water characteristics and fish yield in the eastern Brazilian state of Espírito Santo. Note that lakes are very similar except in Tilapia yield and depth.

\begin{tabular}{ccccc}
\hline Characteristic & & Lake & Aguiar \\
\hline Surface area (ha) & & Palminhas & Palmas & 960 \\
Maximum Depth (m) & 800 & 1200 & 10 \\
Tilapia Yield (tons year ${ }^{-1}$ ) & & 24 & 51 & 120 \\
Food Conversion Rate & & 710 & 161 & 1.6 \\
Dissolved Oxygen $\left(\mathrm{mg} \mathrm{L}^{-1}\right)$ & We & $7.3 \pm 0.4$ & $7.5 \pm 1.02$ & $8.6 \pm 0.8$ \\
& Dr & $6.5 \pm 1.7$ & $6.1 \pm 1.4$ & $7.7 \pm 1.0$ \\
Temperature $\left({ }^{\circ} \mathrm{C}\right)$ & We & $27.5 \pm 0.7$ & $28.5 \pm 0.7$ & $28.3 \pm 0.8$ \\
& Dr & $25.0 \pm 0.3$ & $24.8 \pm 0.2$ & $24.5 \pm 0.4$ \\
& We & $7.0 \pm 0.2$ & $7.3 \pm 0.2$ & $7.4 \pm 0.4$ \\
Conductance $\left(\mathrm{mS} \mathrm{cm}^{-1}\right)$ & Dr & $6.4 \pm 0.3$ & $6.2 \pm 0.4$ & $6.7 \pm 0.4$ \\
& We & $64.0 \pm 2.5$ & $72.5 \pm 4.0$ & $64.0 \pm 3.0$ \\
& Dr & $70.0 \pm 6.8$ & $90.0 \pm 7.7$ & $83.5 \pm 4.0$ \\
\hline
\end{tabular}

and Palminhas $\left(19^{\circ} 24^{\prime} 44^{\prime \prime} \mathrm{S}, 40^{\circ} 12^{\prime} 07^{\prime \prime} \mathrm{W}\right)$. These dendritic lakes were formed in the Tertiary sediments of the Barreiras formation (Esteves et al. 1995) and are fed by rainfall and several tributaries, and their outlets drain into the Doce River. The lakes are similar in that there are few adjacent residences they accommodate some leisure use by both individuals and groups (clubs), and agricultural areas occur nearby, including pasture and coffee and banana plantations along with some farms and fragments of native forest.

Palmas Lake (1200 ha) is at most $51 \mathrm{~m}$ deep with one tilapia cage farm with a volume of $1117 \mathrm{~m}^{3}$ and an annual production of $161 \mathrm{t}$ of fish since 2011. Palminhas Lake (800 ha) is $24 \mathrm{~m}$ deep and has four separate fish cage farms with volumes of 540 to $1176 \mathrm{~m}^{3}$ and an annual production of ca. $710 \mathrm{t}$; production at this farm started in 2006. Aguiar Lake (960 ha) is the shallowest, at $8-10 \mathrm{~m}$ deep, with a single $204 \mathrm{~m}^{3}$ cage farm, established in 2008, with an annual production of approximately $120 \mathrm{t}$ (Tab. 1).

Climate in the region is tropical and seasonally hot and humid with an annual average temperature of $23{ }^{\circ} \mathrm{C}$ and a monthly temperatures that vary between $19{ }^{\circ} \mathrm{C}$ and $32^{\circ} \mathrm{C}$. The average annual rainfall is $600 \mathrm{~mm}$ and mostly falls during the hotter months of the year, with colder months being relatively dry (INCAPER 2012). The three lakes are located in similar geological conditions (Bozelli et al. 1992; Barroso et al. 2014) and are compared in Table 1.

\subsection{Study design}

During each season (wet and dry), we sampled all lakes four times each, December 2012 and January 2013 for the wet season, and in June and July 2013 for the dry season. During each collection, we took paired samples, one within the fish culture and one at least $1 \mathrm{~km}$ from the fish culture (the control).

We measured in situ water conditions, including dissolved $\mathrm{O}_{2}$, $\mathrm{pH}$, conductivity and temperature with a multiparameter Horiba U52-G (Horiba Ltd., Kyoto, Japan). A volume of $500 \mathrm{~mL}$ of water was collected from a depth of $1 \mathrm{~m}$ and analyzed in the laboratory to quantify the total ammonia, phosphorus, chlorophyll $a$ and phycocyanin. Ammonia was evaluated using the indophenol method and phosphorus was determined by the ascorbic acid method (Apha 1998). Chlorophyll $a$ was extracted with acetone/methanol and read on an Aquafluor (Turner Designs, Sunnyvale, CA, USA) digital fluorometer using the EPA 445.0 method. Phycocyanin was quantified in the specific Aquafluor digital fluorometer channel. These methods from the preparation of glassware to sample collection, storage and analysis followed Apha (1998).

To characterize the phytoplanktonic community, we collected $2 \mathrm{~L}$ of water in Van Dorn bottles at 1, 5 and $10 \mathrm{~m}$ depths at three different locations (for nine samples per point and time). During the entire collection period a total of 432 samples were acquired (three lakes, two points, three depths, three samples each, four times per season during two seasons); they were subsequently fixed in acetic Lugol's solution and stored in the dark. To estimate the species richness the algae were identified under optical microscopy $(400 \times$ and $1000 \times)$ and were classified following Round (1983). Identification was to the lowest taxonomic level possible using appropriate species keys (Bicudo and Menezes 2006). Phytoplankton counts were carried out with a $25 \mathrm{~mL}$ sedimentation chamber under an inverted microscope following Utermöhl (1958). The count was conducted randomly. We counted all species within a sample and stopped counting when the number of the most common species reached 100 (Lund et al. 1958).

\subsection{Data analysis}

We compared the water chemistry between the control areas and those used to farm tilapia using Student's t-test or a multivariate Hotelling's $T^{2}$ test as appropriate and depending on the correlational structure of the variables. We compared the lakes to test whether they could be joined in the analyses, and if so, they were treated as blocks in the analysis of variance. If they were too different, we compared the control and tilapia treatments by lake. We also compared how the lakes varied over time between the two seasons under investigation. We did not use repeated measures ANOVA because of the collection regime, which did not always include all test locations on the same dates in all treatments, and because of the large difference between the sampling events in the two seasons. Additionally, we were less concerned about the time 

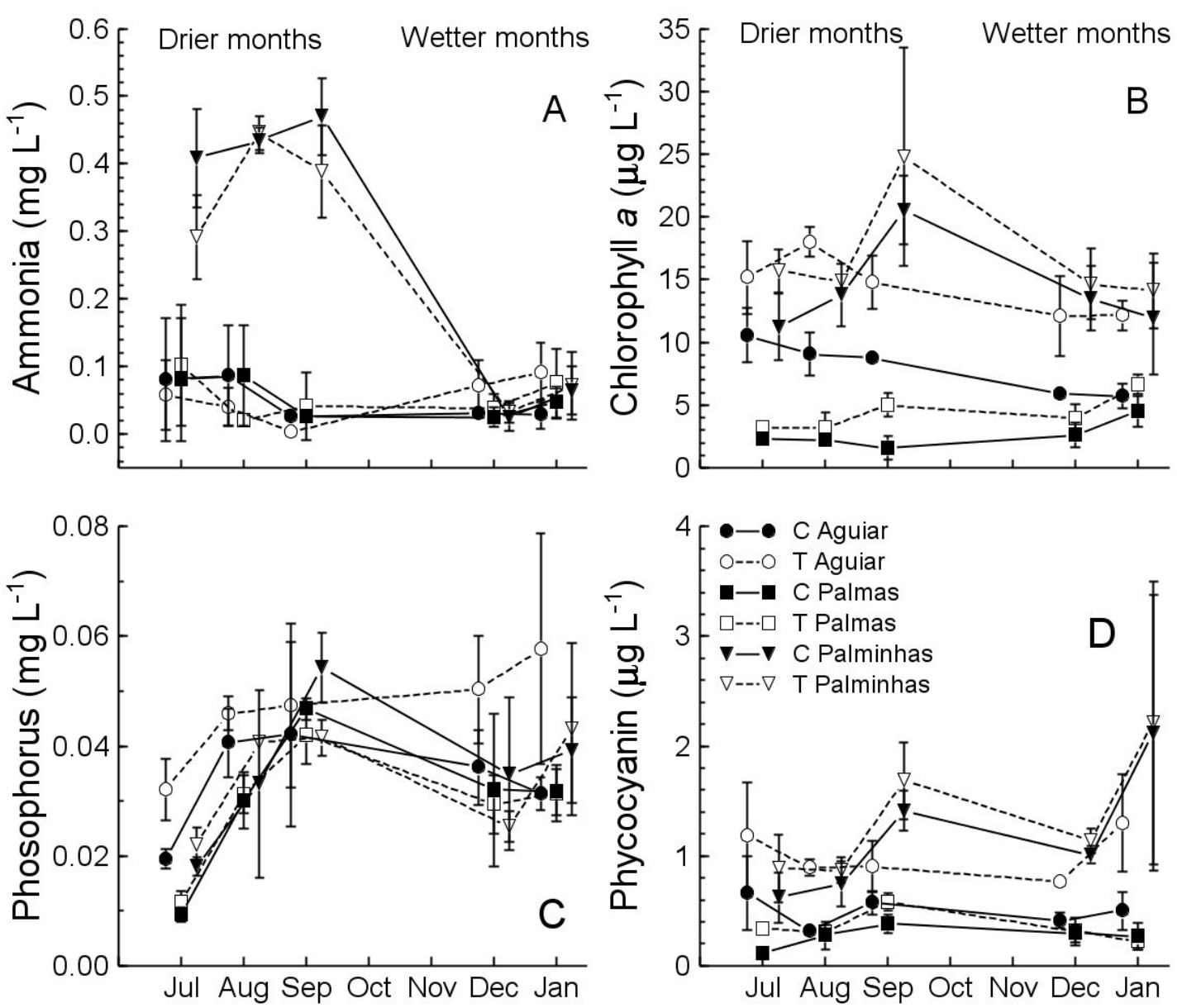

Month

Fig. 1. Chemical composition (mean and 95\% confidence intervals) of the water measured over time and compared between treatments (the letter $\mathrm{C}$ and $\mathrm{T}$ in the legend indicate control and tilapia cage farming) and lakes (following the letters $\mathrm{C}$ and $\mathrm{T}$ ) from July to February (winter to summer in the Southern Hemisphere), illustrating that variation within each lake over time can be greater than that between treatments. These measurements are summarized by month rather than season to provide more information about trends over time.

component than we were about the differences between the treatments within each lake.

Next, we similarly compared the algae assemblages between the two treatments. In this comparison, we used the package Biodiversity $\mathrm{R}$ in the program $\mathrm{R}$ (version 3.2.2) to generate species accumulation curves to compare the expected species richness by treatment. We also searched for algal species that were unique to any lake, treatment or their combination to explain how assemblages might change with respect to tilapia farming.

\section{Results}

\subsection{Water chemical response to tilapia}

Treatments had some similar and different tendencies with respect to the four chemical measurements we used and depending upon which lake and season was being investigated (Fig. 1, Tab. 2). Ammonia concentration, for example, was relatively constant between the two seasons, although in Palminhas Lake, the concentrations increased in both treatments in the cooler months of July through September, and more so in the control. The other two lakes remained more or less the same and at times were different between the control and tilapia treatments, yet those differences were not consistently in any given direction (Fig. 1A, Tab. 2).

The chlorophyll a concentration also varied more in Palminhas Lake, although it was similar in the control and tilapia treatments, with an increase in September. In Aguiar Lake, the chlorophyll $a$ was consistently greater in the tilapia treatment than in the control, and both of these were greater than in Palmas Lake. In Palmas Lake, as in Palminhas, chlorophyll $a$ tended to be greater in the tilapia treatment and remained at the lowest values all year long (Fig. 1B, Tab. 2).

Phosphorus concentrations tended to be greater in Aguiar Lake, where they also tended to be greatest in the tilapia 
Table 2. Comparisons between cage-farming and control treatments of four compound concentrations in the water of three lakes in eastern Brazil. The " $=$ " symbol indicates not statistically different and no apparent trend, both " $<$ " and " $>$ " indicate statistical significance at $P<0.05$ and " $\leq$ " indicates the direction of a difference greater than $10 \%$, while not statistically different (all t-tests were independent because concentrations of compounds were uncorrelated at collection points over time, Fig. 1).

\begin{tabular}{ccccc}
\hline \multirow{2}{*}{ Compound } & \multirow{2}{*}{ Season } & \multicolumn{3}{c}{ Lake } \\
\cline { 3 - 5 } & & Aguiar & Palmas & Palminhas \\
\hline \multirow{2}{*}{ Ammonia } & Wet & $\mathrm{C}=\mathrm{F}$ & $\mathrm{C} \leq \mathrm{F}$ & $\mathrm{C}<\mathrm{F}$ \\
& Dry & $\mathrm{C}<\mathrm{F}$ & $\mathrm{C}=\mathrm{F}$ & $\mathrm{C}=\mathrm{F}$ \\
\multirow{5}{*}{ Chlophyll $a$} & Wet & $\mathrm{C}<\mathrm{F}$ & $\mathrm{C}<\mathrm{F}$ & $\mathrm{C} \leq \mathrm{F}$ \\
& Dry & $\mathrm{C}<\mathrm{F}$ & $\mathrm{C}<\mathrm{F}$ & $\mathrm{C} \leq \mathrm{F}$ \\
\multirow{3}{*}{ Phosphorus } & Wet & $\mathrm{C}<\mathrm{F}$ & $\mathrm{C}=\mathrm{F}$ & $\mathrm{C}=\mathrm{F}$ \\
& Dry & $\mathrm{C}<\mathrm{F}$ & $\mathrm{C}=\mathrm{F}$ & $\mathrm{C}=\mathrm{F}$ \\
Phycocyanin & Wet & $\mathrm{C}<\mathrm{F}$ & $\mathrm{C}=\mathrm{F}$ & $\mathrm{C}=\mathrm{F}$ \\
& Dry & $\mathrm{C}<\mathrm{F}$ & $\mathrm{C}<\mathrm{F}$ & $\mathrm{C} \leq \mathrm{F}$ \\
\hline
\end{tabular}

Note. 10 of $24 \mathrm{C}<\mathrm{F}, 4 \mathrm{C} \leq \mathrm{F}, 9 \mathrm{C}=\mathrm{F}, 1 \mathrm{C}>\mathrm{F}$.

treatments. This was in contrast to the other two lakes where neither a large nor a consistent difference was found between the treatments and controls. The phosphorus in all the lakes increased from July to September and then declined until December. The variability among the months was greater than the differences between the treatments (Fig. 1C, Tab. 2). Finally, phycocyanin also varied among the lakes and was often greater in the tilapia treatment but never in the control (July and September, and for Aguiar, in December and January, Fig. 1D, Tab. 2). Overall, while the water chemistry varied among the lakes, months and treatments, both chlorophyll $a$ and phycocyanin tended to be greater in the tilapia treatments in all lakes (except Palminhas, Figs. 1B, 2D).

\subsection{Phytoplankton assemblage}

A total of 33 species of phytoplankton were identified (Tab. 3), 20 of which were detected in all three lakes and in both treatments. Another nine species were observed in only two lakes (Tab. 4). Three species were found in only one lake and all of these were identified in both treatments: Encyonema perpusillum (Bacillariophyceae) in Palmas and $\mathrm{Mi}$ crocystis wesenbergii and Spirulina subsalsa (Cyanophyceae) in Palminhas. These three unique species were not included in subsequent analyses.

Species accumulation curves showed that a greater number of algae species were observed in the tilapia treatments in Aguiar and Palminhas Lakes, while in Palmas Lake, the species richness in both treatments was the same (Fig. 2). While 20 of the 33 species of algae were found in all lakes, their relative abundance varied somewhat. In a plot of abundance by treatment, abundance tends to appear to be independent of treatment, especially for very abundant species. However, less abundant species are more variable in their abundance by treatment, as seen by the vertical distance between the diagonal line (expected values if abundance is independent of treatment) and each point (Fig. 3). Thus, those species with fewer than 100 counted individuals tend to vary
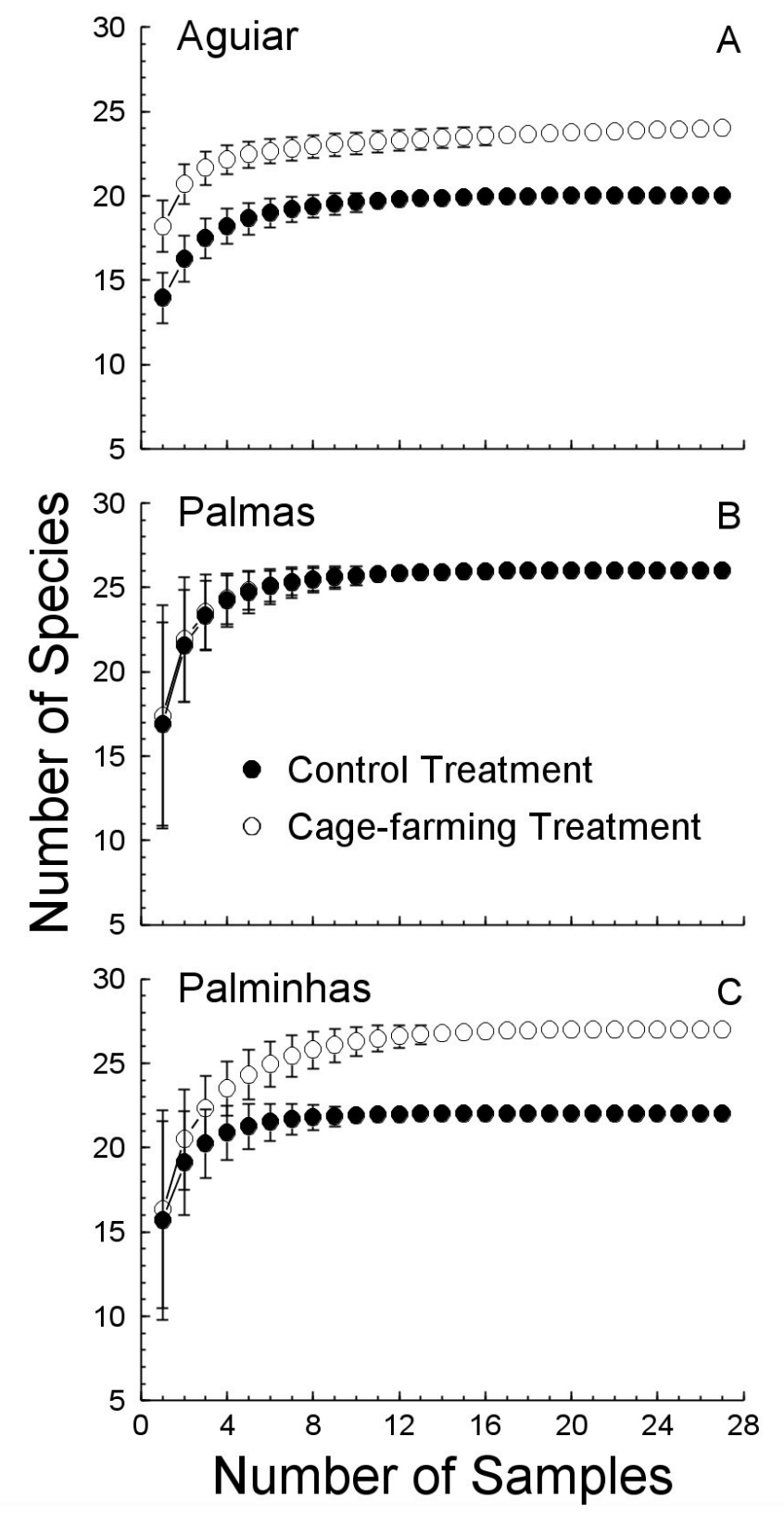

Fig. 2. Species accumulation (rarefaction) curves for the three lakes compared by treatment. In Aguiar and Palminhas Lakes, species richness in the tilapia cage farming treatment is greater than in the control treatment, while in Palmas lake, they are similar.

by treatment, which implies that the less common species are those that are most strongly influenced by the chemical changes in the water caused by fish farming.

Because lakes were different, we separated them in additional analyses. In Lake Aguiar, the estimated species richness was greatest in the fish cage farm treatment (24 versus 20). In Lake Palmas, the estimated species richness (29) was the same in both treatments. Finally, in Lake Palminhas, the estimated species richness was 27 in the fish farm and 22 in the control. Thus, in two lakes, the estimated species richness was greater by $2-3$ species in the cage farm treatments. 
Table 3. Algae species and their relative abundances (\%) by lake and treatment, ordered by class, in the state of Espírito Santo, in eastern Brazil. (C - Control, T - Tilapia farming treatment).

\begin{tabular}{|c|c|c|c|c|c|c|c|}
\hline \multirow{3}{*}{ Class } & \multirow{3}{*}{ Specie } & \multicolumn{6}{|c|}{ Lake } \\
\hline & & \multicolumn{2}{|c|}{ Aguiar } & \multicolumn{2}{|c|}{ Palmas } & \multicolumn{2}{|c|}{ Palminhas } \\
\hline & & $\mathrm{C}$ & $\mathrm{T}$ & $\mathrm{C}$ & $\mathrm{T}$ & $\mathrm{C}$ & $\mathrm{T}$ \\
\hline \multirow{7}{*}{ Bacillariophyceae } & Aulacoseira agassizi & 17.0 & 9.70 & $\overline{0.40}$ & 0.20 & 5.60 & 13.0 \\
\hline & Encyonema perpusillum & & & 0.01 & 0.04 & & \\
\hline & Eunotia $s p$ & 0.40 & 0.80 & 0.10 & 0.10 & 0.04 & 0.03 \\
\hline & Navicula cryptotenella & 0.60 & 1.20 & 0.30 & 0.40 & 0.06 & 0.06 \\
\hline & Urosolenia $s p$ & 0.20 & 0.30 & 1.20 & 0.80 & 0.80 & 4.00 \\
\hline & Ankistrodesmus bernardii & 0.08 & 0.01 & 0.80 & 0.90 & 0.40 & 0.40 \\
\hline & Chlorella vulgaris & 45.0 & 45.0 & 60.0 & 54.0 & 26.0 & 20.0 \\
\hline \multirow{4}{*}{ Chlorophyceae } & Coelastrum reticulatum & & & 0.01 & 0.01 & 0.01 & 0.04 \\
\hline & Crucigenia rectangularis & 0.10 & 2.00 & 0.20 & 0.10 & 0.06 & 0.10 \\
\hline & Golenkinia radiata & 0.02 & & 0.01 & 0.06 & & \\
\hline & Monoraphidium $s p$ & 4.00 & 2.60 & 5.60 & 5.10 & 2.80 & 2.60 \\
\hline \multirow{3}{*}{ Chrysophyceae } & Scenedesmus acuminatus & 0.10 & 0.20 & & & 0.03 & 0.01 \\
\hline & Dinobryon sertularia & 0.10 & & 0.40 & 0.50 & & 0.04 \\
\hline & Anabaena solitaria & 0.20 & 0.04 & 0.10 & 0.10 & 0.50 & 0.60 \\
\hline \multirow{11}{*}{ Cyanophyceae } & Cylindrospermopsis raciborskii & 1.80 & 0.01 & 9.00 & 9.00 & 44.5 & 42.0 \\
\hline & Epigloeosphaera brasilica & 15.0 & 22.5 & 7.50 & 9.50 & 4.40 & 2.70 \\
\hline & Geitlerinema splendidum & 1.40 & 1.50 & 3.00 & 3.00 & 3.30 & 1.80 \\
\hline & Merismopedia glauc & 7.80 & 7.80 & 0.20 & 0.50 & 0.20 & 0.50 \\
\hline & Microcystis aeruginosa & 4.30 & 4.00 & 4.00 & 8.00 & 3.50 & 2.30 \\
\hline & Microcystis wesenbergii & & & & & 0.30 & 0.80 \\
\hline & Oscillatoria curviceps & 0.01 & 0.03 & 0.10 & 0.02 & 0.20 & 0.10 \\
\hline & Phormidium crouani & & & 0.05 & 0.07 & 0.70 & 3.20 \\
\hline & Pseudanabaena galeata & & & 0.05 & 0.05 & 0.10 & 0.20 \\
\hline & adiocystis fernandoi & & & & 0.09 & & 0.04 \\
\hline & Spirulina subsalsa & & & & & 0.01 & 0.02 \\
\hline Dinophyceae & Peridinium umbonatum & 0.30 & 0.10 & 0.10 & 0.20 & 0.20 & 0.10 \\
\hline Euglenophyceae & Trachelomonas volvocin & 1.00 & 1.00 & 0.30 & 0.30 & 0.50 & 0.50 \\
\hline \multirow{6}{*}{ Zignematophyceae } & Cosmarium contractum & 0.60 & 0.50 & 1.70 & 2.00 & 0.06 & 0.30 \\
\hline & Spondylosium panduriformi & & & 0.05 & 0.10 & & 0.01 \\
\hline & Staurastrum forficulatum & & & 0.40 & & 0.01 & \\
\hline & Staurastrum $s p$ & 0.20 & 0.08 & 3.50 & 3.00 & 4.20 & 3.30 \\
\hline & Staurastrum rotula & & & 0.20 & 0.20 & 0.50 & 0.30 \\
\hline & Staurastrum tetracerum & 0.10 & 0.30 & 0.20 & 1.50 & 1.60 & 1.00 \\
\hline
\end{tabular}

Table 4. Algae species that were detected in two lakes only and their abundance (number counted) in each treatment. In the abundance column, $\mathrm{C}$ indicates the control treatment, and $\mathrm{F}$ indicates the cage-farming treatment.

\begin{tabular}{cccc}
\hline Species & Lake & Treatment & Abundance C, F \\
\hline \multirow{2}{*}{ Coelastrum reticulatum } & Palmas & Both & 2,2 \\
& Palminhas & Both & 1,4 \\
Golenkinia radiata & Aguiar & Tilapia & 2,0 \\
& Palmas & Both & 8,3 \\
Phormidium crouani & Palmas & Both & 6,8 \\
& Palminhas & Both & 12,30 \\
Pseudanabaena galeata & Palmas & Both & 6,6 \\
& Palminhas & Both & 13,19 \\
\multirow{2}{*}{ Radiocystis fernandoi } & Aguiar & Tilapia & 0,10 \\
& Palminhas & Tilapia & 0,4 \\
Scenedesmus acuminatus & Aguiar & Both & 29,23 \\
& Palminhas & Both & 5,3 \\
Spondylosium panduriforme & Palmas & Both & 5,21 \\
& Palminhas & Tilapia & 0,5 \\
Staurastrum forficulatum & Palmas & Control & 31,0 \\
& Palminhas & Control & 1,0 \\
Staurastrum rotula & Palmas & Both & 23,31 \\
& Palminhas & Both & 71,51 \\
\hline
\end{tabular}


Table 5. Relative abundance (\%) of the classes of phytoplankton in each treatment by lakes and treatment under study. If rare, we indicate by " $<1 \%$." C - Control, T - Tilapia farming treatment. Empty cells indicate absence.

\begin{tabular}{|c|c|c|c|c|c|c|}
\hline \multirow{3}{*}{ Class } & \multicolumn{6}{|c|}{ Relative abundance (\%) by Lake } \\
\hline & \multicolumn{2}{|c|}{ Aguiar } & \multicolumn{2}{|c|}{ Palmas } & \multicolumn{2}{|c|}{ Palminhas } \\
\hline & $\mathrm{C}$ & $\mathrm{T}$ & $\mathrm{C}$ & $\mathrm{T}$ & $\mathrm{C}$ & $\mathrm{T}$ \\
\hline Bacillariophycea & 18 & 12 & & 1 & 7 & 17 \\
\hline Chlorophycea & 49 & 48 & 66 & 60 & 29 & 25 \\
\hline Chrysophycea & $<1$ & & $<1$ & $<1$ & & $<1$ \\
\hline Conjungatophycea & & $<1$ & $<1$ & $<1$ & $<1$ & $<1$ \\
\hline Cyanophyceae & 31 & 36 & 23 & 30 & 57 & 52 \\
\hline Dinophycea & $<1$ & $<1$ & $<1$ & $<1$ & $<1$ & $<1$ \\
\hline Euglenophyceae & 1 & 1 & $<1$ & $<1$ & $<1$ & $<1$ \\
\hline Zignematophyceae & 1 & 1 & 7 & 7 & 7 & 5 \\
\hline
\end{tabular}

As seen by the confidence intervals of the rarefaction curves, the cage farm treatment had statistically greater species richness in Aguiar and Palminhas Lakes (Fig. 2).

Relative abundances of the members of the phytoplankton community in the three lakes are shown in Table 5. In Palmas Lake, the Chlorophyceae had the greatest abundance, followed by Cyanophyceae. In Palminhas Lake, Cyanophyceae was the most abundant class in both the control and cage farming treatments. Chlorophyceae was the second most frequent class. In Lake Aguiar, Chlorophyceae was the most abundant class, followed by Cyanophyceae.

\section{Discussion}

Tilapia cage farming has an effect on both the composition of the phytoplankton assemblage and water chemistry, but natural local variability in both species and chemistry tends to complicate these patterns. In all lakes, despite this natural variability, nitrogen, phosphorus, chlorophyll $a$ and phycocyanin all tended to be in greater concentrations in the cage farm treatments than in the control (away from the farm). Thus, there is a clear influence of fish cage farming on important chemical concentrations in the lakes. Climate also influences the water chemistry, as expected (Mallasen et al. 2012; Suhet and Schocken-Iturrino 2013). In these and other tropical lakes, seasons are more strongly influenced by rainfall than temperature. Thus, rainfall here is likely to drive the large differences in concentrations seen over the course of the year (Guo and $\mathrm{Li}$ 2003; Gomes et al. 2006; Degefu et al. 2011). While the concentrations varied among the lakes, treatments and over time, the natural concentrations were similar to those observed in other lakes in Brazil (Santos et al. 2010; Leonardo et al. 2011).

Variation in ammonia concentration was surprising because in the drier months it was much greater in Palminhas Lake yet converged in the rainy season with the other two lakes. The other two lakes maintained a relatively low and constant ammonia concentration over time (Fig. 2). We expected phosphorus to be important in these lakes (Johansson and Nordvarg 2002; Guo et al. 2009) due to its effect on the growth of freshwater phytoplankton. We also expected phosphorus to be extremely variable and more concentrated in the

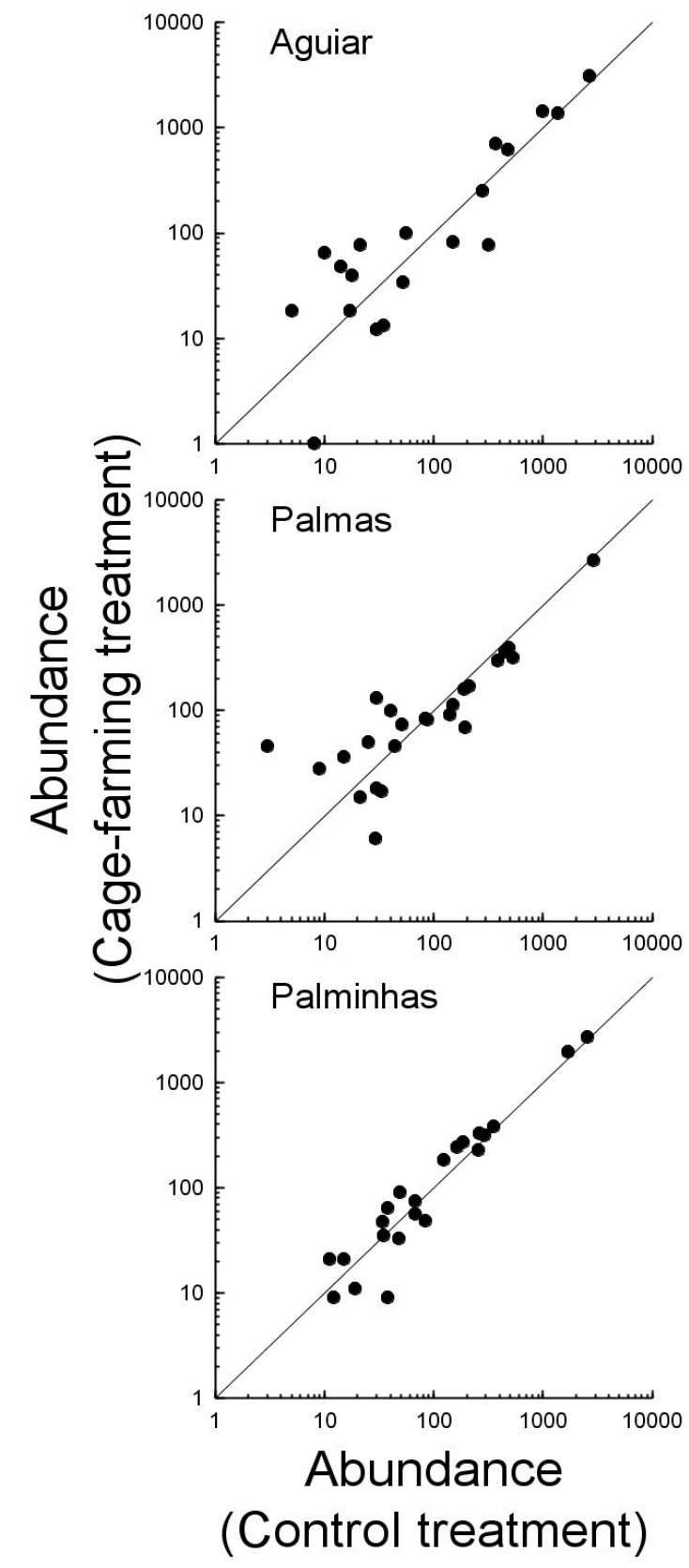

Fig. 3. Species abundance (frequency) curves ( $\log _{10}$ by $\log _{10}$ plot) by lake showing that the rarer species tend to be those that respond more to tilapia farming than the more abundant species. Note, the order of abundance varies somewhat among the lakes, and thus species are not necessarily in the same order in the three figures. Each point is a species and where it lies on each axis is the number of individuals found in each treatment.

cage farms because of its presence in the fish food (Ferraris et al. 2006). However, while phosphorus tended to be more concentrated in the cage farm treatments, its variation over time and among the lakes was greater than that between the treatments in the same lake. Thus, some evidence suggests that phosphorus can be influenced by cage farms, and further 
experimental study will be required to address this question more directly.

Chlorophyll $a$ is usually a good indicator of the quantity of phytoplankton in the water (Rojas et al. 2004), yet again there was large variation among the lakes. Additionally, one lake (Palminhas) tended to have greater, but more variable, concentrations than the other lakes, while Palmas had lower concentrations all year long. Phycocyanin, an indicator of Cyanophyceae in the water, also varied over time and tended to be greater in Palminhas Lake. Cylindrospermopsis raciborskii (Cyanophyceae) was consistently more abundant in Palminhas Lake, which may have been due to the greater levels of ammonia in the drier months of the study. This hypothesis is supported by the high ammonia uptake capacity of this species (Padisa'k 1997). Additionally, there was no consistent difference in the concentrations between the treatments. Phycocyanin was also low during the same months in Palminhas Lake.

The greater concentration of Cyanophyceae algae observed in Palminhas Lake (Tab. 3) can be detrimental to the aquatic ecosystem due to changes they cause in the dissolved oxygen and pH (Paerl and Paul 2012; O'Neil et al. 2012). Dominance by Cyanophyceae over the other classes of algae may be a consequence of their ability to withstand eutrophic conditions. Cyanophyceae can store phosphorus intracellularly, which allows them to continue growing when environmental phosphorus is otherwise limiting. They can also fix atmospheric nitrogen and have intracellular aerotopes (gas vesicles) that are used for vertical movement in the water column to take advantage of better light and nutrient conditions (Defeju et al. 2011). Thus, the alga Cylindrospermopsis raciborskii, seen predominantly in Palminhas Lake, is common in eutrophic environments and produces its own toxins that also add to the pollution problem (Sant'anna et al. 2006; Rogers et al. 2007).

Phytoplankton species richness was constant in these lakes and tended to have reached the total number of species expected after only 10 samples. While the cage farm treatments tended to have 2-3 more species (except for Palmas Lake), those additional species were not necessarily the same in both lakes. Additionally, the most common species tended to have similar concentrations in both treatments. Thus, while clearly suggesting consequences due to tilapia farming in these lakes, the importance of this impact is not as clear.

Both biotic and abiotic conditions indicate that the waters of Palminhas Lake are becoming enriched. This lake has a greater amount of cage farming and the greatest fish production, indicating that Palminhas Lake has a much greater input of fish feed which contributes to its lower water quality (Venturoti et al. 2015). Additionally, there may be cumulative effects as well, as Palminhas Lake cage farms have been in place since 2006. The water in Palmas Lake, on the other hand, appeared to be the least polluted, which is likely associated with the smaller scale of cage farming as well as its shorter history (began in 2009).

Algae in the class Chlorophyceae tend to be dominant under oligotrophic conditions, such as in Palmas Lake. Chlorella vulgaris, a member of this class, was dominant in Aguiar Lake. This species is known to become dominant when the nitro- gen concentration in the water increases (Huszar et al. 2006). Thus, perhaps the presence of the cage farm, and the associated source of ammonia, indicates a deteriorating situation in Aguiar Lake as well. Also in Aguiar Lake, seasonality was less pronounced and the collection points tended to have similar results. Part of these differences may be due to the shallower water and smaller surface area of this lake. Aguiar Lake has been described as a coastal plain lake with homogeneous waters and a strong influence of winds (Bozelli et al. 1992).

Cyanophyceae tended to increase while Chlorophyceae decreased in the cage farm treatments, especially in Palmas Lake. Because we already know that Cyanophyceae tend to dominate perturbed or polluted environments, it is clear that cage farming contributes to this effect. Part of this contribution may be a consequence of the shading caused by the cages as well as the increase in suspended solids, all of which may favor the Cyanophyceae (Sant' anna et al. 2006).

In summary, tilapia cage farming clearly influences local water conditions in these three relatively small lakes in eastern Brazil. The same pattern has been observed in other environments used for tilapia culture in cages such as Rosana Reservoir, Brazil (Borges et al. 2010) and Lake Kuriftu, Ethiopia (Gibtan et al. 2008). However, at the same time, within-lake variation in conditions, including chemical, as well as depth and surface area also have their own effects on water characteristics and the consequent algal community composition, species richness and abundance. Thus, to ensure that tilapia cage farming (and possibly other kinds of fish farming) does not become a source of pollution in the lakes, we recommend careful and standardized monitoring of the water chemistry (especially the compounds we include here) over time. With climate change also likely to play a role and the strong interaction between water temperatures and chemical characteristics, periodic monitoring will allow us to discover, and solve, problems as they arise.

Acknowledgements. We thank the Fundação de Amparo a Pesquisa dos Espírito Santo (FAPES) for the student fellowship for TOM, the Conselho Nacional de Desenvolvimento Científico e Tecnológico (CNPq) for financial support and the productivity fellowship granted to JJR and LCG.

\section{References}

Apha, 1998, Standard Methods for the examination of water and wastewater. Washington. American Public Health Association, American Water Works Association, Water Environmental Federation.

Barroso G.F., Gonçalves M.A., Garcia F.D.C., 2014, The Morphometry of Lake Palmas, a Deep Natural Lake in Brazil. PLoS ONE. 9(11), e111469.

Bicudo C.E.M., Menezes M., 2006, Gêneros de algas de águas continentais do Brasil (chave para identificação e descrições). Segunda edição, São Carlos, RiMa.

Borges P.A.F., Train S., Dias J.D., Bonecker C.C., 2010, Effects of fish farming on plankton structure in a Brazilian tropical reservoir. Hydrobiol. 649, 279-291. 
Bozelli R.L., Esteves F.A., Roland F., Suzuki M.S., 1992, Padrões de funcionamento das lagoas do baixo Rio Doce: variáveis abióticas e Clorofila-a (Espírito Santo - Brasil). Acta Limnol. Bras. IV, 1331.

Bueno G.W., Ostrensky A., Canzi C., Matos F.T., Roubach R., 2013, Implementation of aquaculture parks in Federal Government waters in Brazil. Rev. Aquac. 5, 1-12.

Bricker S.B., Longstaff B., Dennison W., Jones A., Boicourt K., Wicks C., Woerner J., 2008, Effects of nutrient enrichment in the nation's estuaries: a decade of change. Harmful Algae. 8, 21-32.

Defegu F., Mengistu S., Schargel M., 2011, Influence of fish cage farming on water quality and plankton in fish ponds: A case study in the Rift Valley and North Shoa reservoirs, Ethiopia. Aquaculture. 316, 129-135.

Esteves F.A., Suzuki M.S., Callisto M.F.P., Peres-Neto P.R., 1995, Teores de matéria orgânica, carbono orgânico, nitrogênio, fósforo e feopigmentos no sedimento de alguns ecossistemas lacustres do litoral do estado do Espírito Santo. UFRJ - Rio de Janeiro. Oecologia Bras. 1, 407-17.

Ferraris R.P., Coloso R., Sugiura S., Fliming G., 2006, Phosphorus in effluents from raibow trout (Oncorhynchus mykiss) aquaculture. World Aquac. 37, 16-20.

Gomes L.C., Chagas E.C., Martins-Junior H., Roubach R., Ono E.A., Lourenço J.N.P., 2006, Cage culture of tambaqui (Colossoma macropomum) in a central Amazon floodplain lake. Aquaculture. 256, 374-384.

Gibtan A., Getahun A., Mengistou S., 2008, Effect of stocking density on the growth performance and yield of Nile tilapia [Oreochromis niloticus (L., 1758)] in a cage culture system in Lake Kuriftu, Ethiopia. Aquac. Res. 39, 1450-1460.

Guo L., Li Z., 2003, Effect of nitrogen and phosphorus from fish cage on the communities of shallow lake in middle Yangtze River basin of China. Aquaculture. 226, 201-212.

Guo L., Li Z., Xie P., Ni L., 2009, Assessment effects of cage culture on nitrogen and phosphorus dynamics in relation to fallowing in a shallow lake in China. Aquac. Int. 17, 19-41.

Huszar V., Caraco N., Roland F., Cole J., 2006, Nutrient-chlorophyll relationshipsin tropical-subtropical lakes: do temperate models fit? Biogeochem. 79, 239-250.

Instituto Capixaba de Pesquisa, Assistência Técnica e Extensão Rural. INCAPER (2012), http://hidrometeorologia.incaper.es. gov.br/index.php. Accessed 12 March 2015.

Jieng Z., Liao Y., Liu J., Shou L., Chen Q., Yan X., Zhu G., Zeng J., 2013, Effects of fish farming on phytoplankton community under the thermal stress caused by a power plant in a eutrophic, semienclosed bay: Induce toxic dinoflagellate (Prorocentrum minimum) blooms in cold seasons. Mar. Pollut. Bull. 76, 315-324.

Johansson T., Nordvarg L., 2002, Empirical mass balance models calibrated for freshwater fish farm emissions. Aquaculture. 212, 191-211.

Leonardo A.F., Corrêa C.F., Baccarin A.E., 2011, Qualidade da água de um reservatório submetido à criação de tilápias em tanquesrede, no sul de São Paulo, Brasil. Bol. do Inst. de Pesca. 37(4), 341-54.

Lund J.W.G., Kipling C., Lecren E.D., 1958, The inverted microscope method of estimating algal number and the statistical basis of estimation by counting. Hydrobiol. 11, 143-170.
Mallasen M., Barros H.P., Traficante D.P., Camargo A.L.S., 2012, Influence of a net cage tilapia culture on the water quality of the Nova Avanhandava reservoir, São Paulo State, Brazil. Acta Sci. Biol. Sci. 34, 289-296.

O'neil J.M., Davis T.W., Burford M.A., Gobler C.J., 2012, The rise of harmful cyanobacteria blooms: The potential roles of eutrophication and climate change. Harmful Algae. 14, 313-334.

Padisa' k J., 1997, Cylindrospermopsis raciborskii (Woloszynska) Seenayya et Subba Raju, an expanding, highly adaptative cyanobacterium: worldwide distribution and review of its ecology. Arch Hydrobiol 107, 563-593.

Paerl H.W., Pau V.J., 2012, Climate change: Links to global expansion of harmful cyanobacteria. Water Res. 46, 1349-1363.

Rogers E.H., Zehr, R.D. Gage, M.I. Humpage, A.R. Falconer, I.R., Marr M., Chernoff N., 2007, The cyanobacterial toxin, cylindrospermopsin, induces fetal toxicity inthe mouse after exposure late in gestation. Toxicon. 49, 885-864.

Rojas N.E.T., Mainardes-Pinto C.S.R., Rocha O., Silva A.L., 2004, Larviculture of Oreochromis niloticus Linnaeus, 1758 (Perciformes, Cichlidae) in ponds with different levels of water alkalinity. Acta Limnol. Bras. 16, 341-349.

Round, F., 1983, Biologia das Algas. Guanabara, Rio de Janeiro.

Sant'anna C.L., Azevedo M.T.P., 2000, Contribution to the knowledge of potentially toxic Cyanobacteria from Brazil. Nova Hedwig. 71, 259-285.

Sant'anna C.L., Gentil R.C., Silva D., 2006, Comunidade Fitoplanctônica de Pesqueiros da Região Metropolitana de São Paulo. In: Esteves K.E., Sant'anna C.L. (Eds.) Pesqueiros sob uma Visão Integrada de Meio Ambiente, Saúde Pública e Manejo, São Carlos, São Paulo, pp. 49-62.

Santos R.M., Negreiros N.F., Silva L.C., Rocha O., SantosWisniewski M.J., 2010, Biomass and production of Cladocera in Furnas Reservoir, Minas Gerais, Brazil. Braz. J. Biol. 70, 879887.

Sidik M.J., Rashed-Un-Nabi M., Hoque M.A., 2008, Distribution of phytoplankton community in relation to environmental parameters in cage culture area of Sepanggar Bay, Sabah, Malaysia. Estuar. Coast and Shelf. Sci. 80, 251-260.

Suhet M.I., Schocken-Iturrino R.P., 2013, Physical and chemical water parameters and Streptococcus spp. occurrence in intensive tilapia farming in the State of Espírito Santo, Brazil. Acta Sci. $35,29-35$.

Utermohl H., 1958, Zur Vervollkomnung der quantitativen Phytoplankton-Methodik. Verhandlungen Internationale Vereinigung für Theoretische und Angewandte. Limnol. 9, $1-38$.

Venturoti G.P., Veronez A.C., Salla R.V., Gomes L.C., 2015, Variation of limnological parameters in a tropical lake used for tilapia cage farming. Aquac. Rep. 2, 152-157.

Wu M., Huang S., Zang C., Du S., Scholz M., 2012, Release of nutrient from fish food and effects on Microcystis aeruginosa growth. Aquac. Res. 43, 1460-1470. 